\title{
Microstructures in Amorphous $\mathrm{Nb}_{3} \mathrm{Ge}$ Films
}

\author{
(Extended Abstract only) By G. C. CHi and R. J. Schutz, Bell Laboratories, Murray Hill, NJ 07974, USA
}

(Received 3 November 1977; accepted 17 May 1978)

In amorphous $\mathrm{Nb}_{3} \mathrm{Ge}$ films made by $\mathrm{DC}$ getter sputtering, small-angle $\mathrm{X}$-ray scattering indicated that amorphous oxide clusters were present.

Superconducting $\mathrm{Nb}_{3} \mathrm{Ge}$ films (Gavaler, 1973; Testardi, Wernick \& Royer, 1974) were prepared by DC getter sputtering onto a cold ( $300 \mathrm{~K})$, amorphous $\mathrm{SiO}_{2}$ substrate. Films, approximately $1 \mu \mathrm{m}$ thick, were carefully examined by largeangle $X$-ray scattering using a Huber camera in the SeemanBohlin geometry. The X-ray diffraction patterns exhibited three broad peaks and no crystalline reflections (Chencinski \& Cadieu, 1974). The intensity of small-angle X-ray scattering (SAXS) from these amorphous $\mathrm{Nb}_{3}$ Ge films on $\mathrm{SiO}_{2}$ substrate were measured for $0 \cdot 01 \AA^{-1} \leq|\mathbf{K}| \leq 0 \cdot 1 \AA^{-1},(|\mathbf{K}|=$ $4 \pi \sin \theta(\lambda)$ with $\mathrm{Cu} K \alpha$ radiation and a Kratky camera. With proper corrections for substrate scattering and absorption (Chi \& Cargill, 1976), the radius of gyration for the scattering regions was obtained from a Guinier plot and found to be $71 \AA$. The radii of gyration for samples, which were heat treated for $5 \mathrm{~h}$ at $550,620,690$ and $735^{\circ} \mathrm{C}$ in a vacuum system $\left(10^{-6}\right.$ torr $)$, were $83,85,88$ and $127^{\circ} \AA$ respectively. The large-angle diffraction patterns for samples annealed at $690^{\circ}$ and $735^{\circ} \mathrm{C}$ showed crystalline reflection lines. In both cases, detailed examination of the crystalline pattern clearly indicated that most of the sample was of $\mathrm{Nb}_{5} \mathrm{Ge}_{3}$ phase. Some reflection lines may also be attributed to $A 15 \mathrm{Nb}_{3} \mathrm{Ge}$, $\mathrm{GeO}_{2}$ and $\mathrm{NbO}$. The X-ray patterns for crystallized samples and Rutherford back-scattering measurements confirmed that there was oxygen in the sample. These observations indicated that amorphous oxide clusters were the major microstructures in these amorphous $\mathrm{Nb}_{3} \mathrm{Ge}$ films.

The full paper will be submitted to Materials Science and Engineering.

\section{References}

Chencinski, N. \& Cadieu, F. J. (1974). J. Low Temp. Phys. 16, 507-517.

Chi, G. C. \& Cargill, G. S. (1976). Mater. Sci. Eng. 23, $155-159$.

Gavaler, J. R. (1973). Appl. Phys. Lett. 23, 480-482.

Testardi, L. R., Wernick, J. H. \& ROYer, W. A. (1974). Solid State Commun. 15, 1-4.

J. Appl. Cryst. (1978). 11, 620-621

\section{Small-Angle X-ray Scattering on Ferromagnetic Colloids}

(Extended Abstract only) By R. ANTHORE and C. Petipas, Université de Rouen, X-ray' Laboratory', ERA 258, 76130 MontSaint-Aignan, France

(Received 3 November 1977; accepted 25 April 1978)

The size distribution and the structure of colloidal cobalt particles in toluene, as well as interparticle correlations, have been studied.

Ferrofluids are colloidal suspensions of ferromagnetic monodomain grains in thermal equilibrium with a nonmagnetic and insulating fluid. We are using magnetic colloids of cobalt in toluene obtained from the thermal decomposition of cobalt octacarbonyl in the presence of a terpolymer dissolved in toluene (Liebert, Martinet \& Strzelecki, 1972).

A quantitative analysis of electron micrographs shows that the radius distribution of cobalt spheres corresponds to a log-normal law with a mean radius $\bar{R}$ of about $52 \AA$.

The experimental magnetization curve may be described by Langevin curves weighted by a coefficient proportional to the log-normal law, $F(R)$, (Anthore, Petipas, Chandesris \& Martinet, 1977): $\bar{R}_{m}=46 \AA ; \sigma=1 \cdot 28 . \bar{R}_{m}$ is always smaller than $\bar{R}$.
Size distributions and structure of particles: Let $j_{n}(S)$ be the normalized function. The $\log j_{n}(s)$ versus $s^{2}$ curve shows a good linearity, which is characteristic of a small variation in the particle size, but the experimental curves $s^{3} j_{n}(s)$ have a non-standard form. They tend towards a smaller limiting value than that which would be expected in connection with the discontinuity between pure cobalt and toluene; again it decreases with the aging time at constant radius of gyration. The experimental values are given in Table 1 .

The volume fraction $\beta$ occupied by the particles can be calculated by different methods: $\beta_{\text {abs }}$ is the value determined from the absorption measurement of the incident beam, $\beta_{Q_{0}}$ that from the integrated intensity $\left(\beta_{Q_{Q}}=4.2 \times 10^{-3}\right)$, $\beta_{G}$ that from the intensity $j_{n}(0)\left(\beta_{G}=4.1 \times 10^{-3}\right)$, and $\beta_{M}$ that from the magnetization at saturation; $\beta_{\mathrm{ch}}$ is calculated from the quantity of cobalt octacarbonyl decomposed $\left(\beta_{\mathrm{ch}}=\right.$ $\left.4.6 \times 10^{-3}\right)$. The difference between $\beta_{M}$ and the other values reveals that a fraction of cobalt cannot be considered as free 